\title{
Cognitive and Metacognitive Reading Strategies Training in EFL Reading
}

\author{
Xiufeng Zhang ${ }^{1, *}$ and $\mathrm{Lu} \mathrm{Guo}^{2, \mathrm{a}}$
}

\author{
${ }^{1}$ Department of College English, Capital Normal University, Beijing, China \\ ${ }^{2}$ Faculty of Teacher Education, Capital Normal University, Beijing, China \\ a873026580@qq.com \\ *corresponding author
}

\begin{abstract} further justify the significance and necessity of strategy training.

\section{INTRODUCTION}

In recent years, the research on learning strategies has been a heated issue in the field of educators and psychologists. The learning strategies refer to the special thoughts or behaviors that individuals use to help them comprehend, learn or retain new information and it can be differentiated into three categories depending on the level or type of processing involved: social/ affective strategies, cognitive strategies and meta-cognitive strategies [1]. Most learning strategy researches in second language acquisition and learning have been focused on the identification, description and classification of learning strategies, and some researches have tried to instruct or train the learning strategy. The present paper intends to train some cognitive and metacognitive reading strategies to some students from TEFL classroom, and to testify the great effects of learning strategy training in helping learners' language learning, and also try to find out the efficient way on how to conduct learning strategy training.
\end{abstract}

Taking students of two different classes in the School of Continuing Education in a University as subjects, the present paper represents the conduction of training 20 reading strategies and its results. Through one term of training students' reading strategies, it has found that the students' awareness of reading strategy use in experimental group has gotten greater improvement in 18 out of 20 strategies compared with their counterparts in the control group which does not receive the formal training. It has also found that the strategy training is more significant with students with deep motivations than other students. The results of this study

Keywords: cognitive strategy, metacognitive strategy, strategy training

\section{RELATED LITERATURE REVIEW}

\subsection{Learning Strategy and Learning Strategy Training}

A lot of empirical researches abroad have justified the important role played by the learning strategy in second language acquisition and learning. It has already been noted that in order to better understand how a second language acquired, some researchers have investigated the strategies that characterize good language learners [2]. It has been assumed that one of the reasons for the lack of success of some language learners is their limited repertoire and/or inappropriate use of strategies. Studies that have compared good and poor learners in areas other than L2 learning have led to the conclusion that the learning strategy is another variable to be taken into account in any explanation of successful and unsuccessful learning outcomes. In china, a lot of researches on the learning strategy also justified the above conclusions [3] [4] [5] [6].

Once strategies used by good language learners are identified and the strategy use of effective and less effective learners are compared, the questions arise of whether less effective learners can learn or be taught to use strategies to assist their learning. In fact, another assumption underlying researches on learner strategies is that learners' repertoire of strategies can be expanded and refined and that poor learners may benefit from learning how to use strategies utilized to good effect by their more efficient companions. Although this assumption still remains unproven because of the complexity of learning strategy training, results of a lot of studies have shown that such training can influence learners' choice and use of strategies and most researchers are in favor of training learning strategies [1] [2] [3] [7]. As to the goal of learning strategy training, it focuses on improving learners' awareness of strategy use rather than mastering the specific strategy itself and once aware of the significance of a strategy, learners will choose to use it freely without the guidance of the researchers, which helps to develop their ability of self-monitoring and self-regulation [3].

As to the type of learning strategy training, Oxford divided it into three types: awareness training, one-time strategy training and long-term training [7]. Among them, awareness training is also known as conscious -raising or familiarization training, in which, participants become aware of and familiar with the general idea of language learning strategies and the way such strategies can help them accomplish various language tasks, but participants do not have to use the strategies in actual language tasks. One-time strategy training involves learning and practicing one or more strategies with actual language tasks, in which participants are given the value of the strategy, when and how to use it. Long-term strategy training, similar to one-time strategy training, is more prolonged and covers a greater number of strategies and it is likely to be more 
reliability and validity. In the questionnaire, items $\mathbf{1}-\mathbf{- 1 0}$ were about cognitive reading strategies, and items 11 -20 were concerned with meta-cognitive reading strategies. In order to assure the validity, the questionnaire was written in students' mother tongue. Some sample items included: "In English reading, I will translate English in to Chinese"; "I will write a summary after finish the reading". The details of the questionnaire were listed as those in Appendix I.

\subsection{Procedures of Training (Three Stages)}

The training in this study can be divided into three stages:

Stage I: Before the training. The students both from the experimental and control groups were administered a multi-choice reading comprehension test, and then given a cognitive and meta-cognitive reading strategy questionnaire immediately after the test.

Stage II: During the training. Every two weeks, four different strategies listed in the questionnaire will be trained through teacher's explanation and demonstration, students' practice in reading quiz and then evaluation of the strategies training through the students' written report. The format of the report is like that in appendix II. The whole period of training lasted nearly 12 weeks.

Stage III: After the training. At the end of training, the final examination for this term is coming. A questionnaire interview was conducted accompanying with the final examination and students both from experimental and control group were asked to fill out the questionnaire before handing in their papers.

\subsection{Data Collection and Analysis}

There were 20 items in the questionnaire and five options for each item. The option A (Never) scores 1 point, the option B (Sometimes) scores 2 points, C (Often) scores 3 points, D (Usually) scores 4 points and E (Always) scores 5 points. Then, the scores of items about cognitive strategies and of items about meta-cognitive strategies were recorded respectively. The detailed analysis of the data was like the following. As for the students' written report, the 20 strategies were listed in the paper and then the students were asked to select all the strategies they used in each immediately precedent reading comprehension quiz. The scores of students depend on how many strategies they have used in the quiz and each choice of the strategy scores 1 point.

\section{FINDINGS AND DISCUSSION}

The following table I contrasts the scores that students from experimental and control groups get in their reading strategy use before and after the training respectively. 
Table 1 Scores about Reading strategies before and after training

\begin{tabular}{|c|c|c|c|c|c|c|c|}
\hline \multicolumn{2}{|c|}{} & \multicolumn{3}{|c|}{ Experimental group } & \multicolumn{3}{c|}{ Control group } \\
\cline { 3 - 8 } & Pre-test & Post-test & $\begin{array}{c}\text { Gaining } \\
\text { percentage }\end{array}$ & Pre-test & Post-test & $\begin{array}{c}\text { Gaining } \\
\text { percentage }\end{array}$ \\
\hline \multirow{2}{*}{$\begin{array}{c}\text { Reading } \\
\text { strategies }\end{array}$} & $\begin{array}{c}\text { Average } \\
\text { scores }\end{array}$ & $\mathbf{4 9 . 1}$ & $\mathbf{5 7 . 4}$ & $\mathbf{1 7 . 0 \%}$ & $\mathbf{4 7 . 9}$ & $\mathbf{5 2 . 5}$ & $\mathbf{9 . 6 \%}$ \\
\cline { 2 - 8 } & $\begin{array}{c}\text { Standard } \\
\text { deviation }\end{array}$ & $\mathbf{1 0 . 8}$ & $\mathbf{1 2 . 5}$ & & $\mathbf{1 1 . 4}$ & $\mathbf{7 . 5}$ & \\
\hline \multirow{2}{*}{$\begin{array}{c}\text { Cognitive } \\
\text { reading strategies }\end{array}$} & $\begin{array}{c}\text { Average } \\
\text { scores }\end{array}$ & $\mathbf{2 5 . 4}$ & $\mathbf{2 9 . 1}$ & $\mathbf{1 4 . 6 \%}$ & $\mathbf{2 5 . 4}$ & $\mathbf{2 7 . 1}$ & $\mathbf{6 . 7 \%}$ \\
\cline { 2 - 8 } & $\begin{array}{c}\text { Standard } \\
\text { deviation }\end{array}$ & $\mathbf{5 . 6}$ & $\mathbf{6 . 4}$ & & $\mathbf{6 . 7}$ & $\mathbf{5 . 0}$ & \\
\hline \multirow{2}{*}{$\begin{array}{c}\text { Meta-cognitive } \\
\text { reading strategies }\end{array}$} & $\begin{array}{c}\text { Average } \\
\text { scores }\end{array}$ & $\mathbf{2 3 . 7}$ & $\mathbf{2 8 . 4}$ & $\mathbf{1 9 . 8 \%}$ & $\mathbf{2 2 . 5}$ & $\mathbf{2 5 . 4}$ & $\mathbf{1 2 . 9 \%}$ \\
\cline { 2 - 8 } & $\begin{array}{c}\text { Standard } \\
\text { deviation }\end{array}$ & $\mathbf{6 . 6}$ & $\mathbf{7 . 3}$ & & $\mathbf{6 . 2}$ & $\mathbf{4 . 6}$ & \\
\hline
\end{tabular}

From table I, it can be found that students in the experimental group who have received the strategy training gain more scores and more improvement in their reading strategy use (including both the cognitive and metacognitive reading strategy) after the training than their counterpart in the control group who did not receive the straining. For example, in reading strategy use, students from the experimental group scores more after the training than before the training; that is, $(57.4-49.1) / 49.1 \approx 0.17$, the scores of students from the experimental group has increased by 8.3

points or increased by $17 \%$ compared with their scores before the training. However, the scores of students from the control group, $(52.5-47.9) / 47.9 \approx 0.096$, has just increased by 4.6 points or by $9.6 \%$. From the data analysis in table I, it is obvious that the strategy training has achieved the significance, and it has improved the students' awareness of reading strategy use.

In order to know the effects of the training in details, table II displays the contrasting results of scores of each reading strategy before and after the training.

Table 2 scores of specific reading strategy before and after the training

\begin{tabular}{|c|c|c|c|c|c|c|c|c|c|c|c|}
\hline \multirow{2}{*}{$\begin{array}{c}\text { Ite } \\
\text { m } \\
\text { No. }\end{array}$} & \multicolumn{2}{|c|}{ Pre-test } & \multicolumn{2}{|c|}{ Post-test } & \multirow{2}{*}{$\begin{array}{c}\text { gaining } \\
\text { Percentag } \\
\text { e }\end{array}$} & \multirow{2}{*}{$\begin{array}{c}\text { Ite } \\
\text { m } \\
\text { No. }\end{array}$} & \multicolumn{2}{|c|}{ Pre-test } & \multicolumn{2}{|c|}{ Post-test } & \multirow{2}{*}{$\begin{array}{c}\text { gaining } \\
\text { Percentag } \\
\text { e }\end{array}$} \\
\hline & $\begin{array}{c}\text { Averag } \\
\mathrm{e} \\
\text { scores } \\
\end{array}$ & $\begin{array}{c}\text { Standard } \\
\text { deviatio } \\
n\end{array}$ & $\begin{array}{c}\text { Averag } \\
\text { e } \\
\text { scores }\end{array}$ & $\begin{array}{c}\text { Standard } \\
\text { deviatio } \\
\mathrm{n}\end{array}$ & & & $\begin{array}{l}\text { Averag } \\
\text { e } \\
\text { scores }\end{array}$ & $\begin{array}{c}\text { Standard } \\
\text { deviatio } \\
n\end{array}$ & $\begin{array}{l}\text { Averag } \\
\text { e } \\
\text { scores } \\
\end{array}$ & $\begin{array}{c}\text { Standard } \\
\text { deviatio } \\
n\end{array}$ & \\
\hline 1 & 3.94 & 1.27 & 3.31 & 1.29 & $-16 \%$ & 11 & 2.16 & 1.45 & 2.54 & 1.07 & $17.6 \%$ \\
\hline 2 & 3.03 & 1.16 & 3.30 & 1.01 & $8.9 \%$ & 12 & 2.06 & 0.86 & 2 & 0.71 & $-0.03 \%$ \\
\hline 3 & 2.59 & 1.14 & 3.42 & 0.99 & $32.0 \%$ & 13 & 2.5 & 0.96 & 2.96 & 0.92 & $18.4 \%$ \\
\hline 4 & 2.81 & 1.18 & 3.73 & 1.15 & $32.7 \%$ & 14 & 2.13 & 0.96 & 3.04 & 1.11 & $42.7 \%$ \\
\hline 5 & 2.23 & 0.99 & 2.42 & 1.02 & $8.5 \%$ & 15 & 1.88 & 1.02 & 2.81 & 1.06 & $49.5 \%$ \\
\hline 6 & 2.31 & 0.98 & 2.88 & 1.07 & $24.7 \%$ & 16 & 3.06 & 1.17 & 3.38 & 1.02 & $10.5 \%$ \\
\hline 7 & 2.53 & 1.15 & 3 & 1.10 & $18.6 \%$ & 17 & 3.09 & 1.10 & 3.12 & 0.95 & $0.01 \%$ \\
\hline 8 & 1.46 & 0.61 & 2.08 & 0.98 & $42.5 \%$ & 18 & 2.34 & 1.02 & 3.23 & 1.18 & $38.0 \%$ \\
\hline 9 & 2.12 & 0.99 & 2.27 & 0.67 & $7.1 \%$ & 19 & 2.84 & 1.06 & 3.27 & 1.08 & $15.1 \%$ \\
\hline 10 & 2.66 & 0.99 & 3.31 & 1.05 & $24.4 \%$ & 20 & 1.78 & 0.82 & 2.88 & 1.37 & $61.8 \%$ \\
\hline
\end{tabular}

From table II, it can be found that nearly all the strategies have gotten improvement more or less except strategy 1 (gaining percentage is $-16 \%$ ) and strategy 12 (gaining percentage is $-0.03 \%$ ). Strategy $\mathbf{1}$ is stated as "I will translate the reading materials from English to Chinese when undergoing the reading activity", which is a kind of cognitive strategy. It is not strange for this strategy to score less after the training because this strategy is bound to score less with the improvement of students' English proficiency after a term of English learning. Strategy 12 is that "I will evaluate my progress in reading and find ways to improve the weakness". The awareness of using this strategy nearly has no improvement after the training and it needs further studying and training.

The uses of other eighteen strategies have all been improved. However, some of them are improved significantly such as strategy 3, 4, 8,14,15,18 and 20, whose scores have all increased by more than $30 \%$. Among them, strategy 3, 4 and
8 are cognitive strategies as "I will first try to get the general idea of the reading materials through fast reading", "I will first look at the questions and then look for the answer to them in the materials"; strategy 14, 15, 18 and 20 belong to meta-cognitive strategies as "I will choose different strategies according to the different requests of the reading tasks", "I will do some comprehension exercises after finishing a certain material".

Although the uses of eighteen strategies have all been improved more or less, it can be obviously found that some of them are still in low scores even with bigger improvement than before due to the training. For example, the scores of strategy 8,15 and 20 have increased by $42.5 \%, 49.5 \%$ and $61.8 \%$ respectively, but their scores are still quite low, and all of them $(2.08,2.81$ and 2.88 points respectively) are less than 3 points out of total 5 points. It also can be found from Table II that none of the strategies scores more than 4 points out of total 5 points even after the training, so the strategy 
training is necessary to be further conducted.

From the table I, it was found that the standard deviation of strategy use in the experimental group has increased, that is, the difference among students in their reading strategy uses has become intensified. Therefore, on one hand, it can be concluded that the strategy training has positive effects on students' strategy use; on the other hand, it should be pointed out that the strategy training does not have the same effects on every student, and it is more significant with a certain group of students. The present paper introduced the factor of motivation and tried to find out whether there is some correlation between the significance of training and the students' motivation.

Table 3 difference in English learning motivation

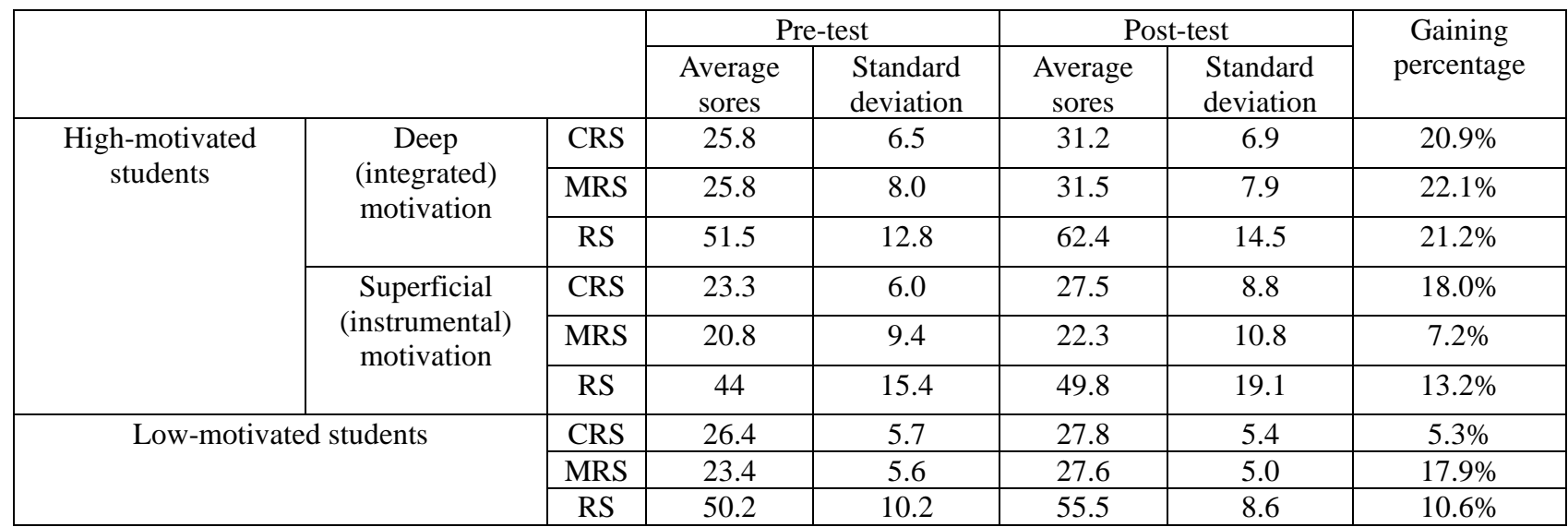

$(\mathrm{CRS}=$ cognitive reading strategies; $\mathrm{MRS}=$ meta-cognitive reading strategies; $\mathrm{RS}=$ reading strategies $)$

From the table III, it can be found that the sub-group of students with prominent deep motivation scores the most in their strategy uses among the three groups, which can be cited to explain why the standard deviation of strategy use in experimental group became bigger. It is due to the fact that the strategy training is more significant with students with prominent deep motivation. As for the other two sub-groups, from the table III, it also can be found that the cognitive strategy training is more significant with the group of students with prominent superficial motivation than with the students with no prominent motivation; however, the students with prominent superficial motivation score less than the students with no prominent motivations in the metacognitive training, that is, the meta-cognitive strategy training is more significant with students with no prominent motivation than those with superficial motivation. These findings still need further testing and studying to justify them.

\section{CONCLUSION}

The present paper reports the conduction of training 20 reading strategies including both cognitive and meta-cognitive reading strategies. As a result, students' awareness of strategy use has been greatly improved after receiving the training. As elaborated in the above, the learning strategy training helps to improve learners' awareness of strategy use and once aware of the significance of a strategy, learners will choose to use it freely without the guidance of the teachers, which helps to develop their ability of self-monitoring and self-regulation. The findings of this
The present paper conducted a motivation test on the students in the experimental group. The device of testing the motivation is to adopted the format of Wen[3] and the detailed format is to look at the appendix II. According to the testing results, students in experimental group was further divided into three sub-group, that is, group of students with deep motivation (or integrated motivation) in prominence, group of students with superficial motivation (or instrumental motivation) in prominence and group of students with no prominence motivation. The table III shows the effects of training on the three sub-groups which has some difference in their English learning motivation. training justify and testify the significance and necessity and importance of strategy training. At the same time, it is also found that the strategy training is more significant with students with deep motivation. Therefore, it may draw the occlusion as the following. On one hand, the strategy training can help to improve the awareness of students' strategy use; on the other hand, strategy training is such a complex project and it is associated with a lot of factors such as students' motivations, and then it is necessary for the strategy training to be further studied, practiced and developed.

\section{REFERENCES}

[1] O’Malley J. M. \& Chamot, A. U. 1990. Learning Strategies in Second Language Acquisition. New York: Cambridge University Press.

[2] Wenden, A.L. 1987.Metacognition: an expanded view on the cognitive abilities of L2 learners. Language Learning, Vol.37, No.4: 573--597

[3] Wang, Lifei \& Wen, Qiufang. 2003. English Learning Strategy Training in China. Foreign language World, (6): 20-26.

[4] Liu, Yichun. 2002. The Difference in Reading Strategy Use between Successful and Unsuccessful Learners. Foreign Language Teaching Abroad, (2): 24-28.

[5] Ma, Guanghui. 1997. The Difference in Learning Strategy Use between High-level and Low-level students. Foreign language World, (2): 38-40.

[6] Ji, Kangli. 2002. Foreign Language Learning and Metacognitive Strategy Training. Foreign language World, 
(2): $20-26$

[7] Oxford, Rebecca L. 1990. Language Learning Strategies: what every teacher should know. Boston: Heinle \& Heinle Publishers.

[8] Knight, S.L., Padron, Y.N. \& Waxman, H.C. 1985. The cognitive reading strategies of ESL students. TESOL Quarterly, Vol.19, P789-792.

[9] Block, E. 1986. The comprehension strategies of second language readers. TESOL Quarterly, Vol. 20, P463-494.

[10] Carrel, P.L. 1989. Meta-cognitive strategy training for ESL reading. TESOL Quarterly, Vol. 23, P647-678.

[11] Phakiti, Aek. 2003. A close look at gender and strategy use in L2 reading. Language Learning, Vol. 53, P649-702

[12] Dong, Qi \& Zhou, Yong \& Chen, Hongbing. 1996. Self-monitoring and Intelligence. Hangzhou: Hangzhou People Press.

[13] Du, Xiaoxin \& Feng, Zhen. 1999. Metacognition and Learning Strategies. Beijing: The People Education Press.

[14] Yang, Xiaohu \& Zhang, Wenpeng. 2002. The Correlation of Metacognition and English Reading Comprehension of Chinese College Students. Foreign Language Teaching and Research, (3): 213-218. 